\title{
Refractory Crohn's disease of the vulva treated with infliximab: A case report
}

\author{
Sapna Makhija MD ${ }^{1}$, Martin Trotter MD PhD FRCPC ${ }^{2}$, Elizabeth Wagner MD FRCPC ${ }^{3}$, \\ Sylvain Coderre MD FRCPC MSc ${ }^{1}$, Remo Panaccione MD FRCPC
}

\begin{abstract}
S Makhija, M Trotter, E Wagner, S Coderre, R Panaccione. Refractory Crohn's disease of the vulva treated with infliximab: A case report. Can J Gastroenterol 2007;21(12):835-837.

Crohn's disease (CD) is a chronic relapsing and remitting inflammatory disorder of the gastrointestinal tract. The common presentation includes abdominal pain, abdominal cramping and diarrhea. Many patients may exhibit systemic symptoms of fever and weight loss. Approximately $20 \%$ to $40 \%$ of patients will experience extraintestinal manifestations that involve the eyes, skin and joints. Women may experience a variety of gynecological manifestations, including vulvovaginal involvement, which is often not recognized and also difficult to treat. A case of refractory vulvovaginal CD is presented and the literature of gynecological manifestations of CD and its treatment are reviewed.
\end{abstract}

Key Words: Crohn's disease; Extraintestinal manifestation; Infliximab; Metastatic Crohn's disease; Treatment

\section{Manifestation vulvaire réfractaire de la maladie de Crohn traitée par infliximab : Rapport de cas}

La maladie de Crohn (MC) est une maladie inflammatoire chronique cyclique du tractus digestif. Le tableau le plus courant inclut : douleurs abdominales, crampes abdominales et diarrhée. De nombreux patients peuvent manifester des symptômes systémiques de fièvre et de perte de poids. Environ $20 \%$ à $40 \%$ des patients éprouveront des manifestations extra-intestinales affectant les yeux, la peau et les articulations. Les femmes peuvent en manifester des signes gynécologiques, notamment l'atteinte vulvo-vaginale, souvent méconnue et difficile à traiter. Les auteurs présentent ici un cas de $\mathrm{MC}$ vulvo-vaginale réfractaire et passent en vue la littérature sur les manifestations gynécologiques de la $\mathrm{MC}$ et leur traitement.
$\mathrm{C}$ rohn's disease $(\mathrm{CD})$ is a chronic relapsing inflammatory disorder of the gastrointestinal tract. Among female patients with Crohn's disease, $24 \%$ may have some form of gynecological association, which may occur before or after the formal diagnosis of CD (1). Gynecological involvement in these patients may include Bartholin gland abscesses, endovaginal fistulas, genital ulcers, or cutaneous $\mathrm{CD}$ involving the vulvovagina, perineum and labia. Female patients often do not discuss these problems with their physicians and, therefore, a delay in diagnosis is common. In addition, these patients can visit a variety of departments, such as gynecology and genitourinary, further delaying the time to their final diagnosis. The potential delay in diagnosing and adequately treating such presentations can lead to significant morbidity and impairment in quality of life. Thus far, treatments for patients with vulvovaginal $C D$ treatments have consisted of antibiotics, topical and systemic steroids, and immunosuppressant agents.

The present paper reviews a case of metastatic vulvar CD, which was refractory to traditional therapy, and responded symptomatically and histologically to infliximab therapy.

\section{CASE PRESENTATION}

A 45-year-old woman was diagnosed with $\mathrm{CD}$ at the time of a laparotomy for free perforation of the sigmoid colon. She underwent ileocecal and sigmoid resection, drainage of an intra-abdominal abscess and diverting colostomy. Postoperatively, she was prescribed oral mesalamine (1 g three times per day). Three months postoperatively, she developed a fistula from the rectal stump to the drain exit site in her right lower quadrant. At repeat laparotomy, she underwent a takedown of the internal fistula, a local rectosigmoid resection and closure of the diverting colostomy.

Three years after the initial diagnosis of CD, she developed right labial swelling, which rapidly progressed to involve the left labia. The area was swollen, erythematous and indurated. No fistulas were recognized. An endovaginal ultrasound and examination under anesthesia failed to show any evidence of fistulas or an underlying abscess. A biopsy of the involved area demonstrated granulomatous vulvitis, consistent with CD of the vulva (Figure 1). The initial treatment included topical steroids and metronidazole, without clinical benefit. Systemic therapy with oral prednisone (40 mg once daily) and subsequent azathioprine $(2.5 \mathrm{mg} / \mathrm{kg} /$ day $)$ for six months failed to result in any clinical improvement. Her luminal disease, which was active with increased stool frequency and lower abdominal cramping, did respond to the combination therapy of steroids and antimetabolites.

A colonoscopy, small bowel follow-through and computed tomography scan of the abdomen and pelvis were performed. During the colonoscopy, apthous ulcerations were noted at the anastamosis (Figure 2) and the rectum. There was also a fistulous opening recognized in the rectum (Figure 3 ). Due to ongoing vulvovaginal symptoms of discomfort and dyspareunia, the decision was made to treat her with infliximab as the primary

${ }^{1}$ Division of Gastroenterology; ${ }^{2}$ Division of Pathology; ${ }^{3}$ Division of Obstetrics and Gynecology, University of Calgary, Calgary, Alberta

Correspondence: Remo Panaccione, University of Calgary, Room 127, 3300 Hospital Drive Northwest, Calgary, Alberta T2N 4N1.

Telephone 403-210-9837, fax 403-270-7287, e-mail rpanacci@ucalgary.ca

Received for publication August 4, 2006. Accepted November 30, 2006 


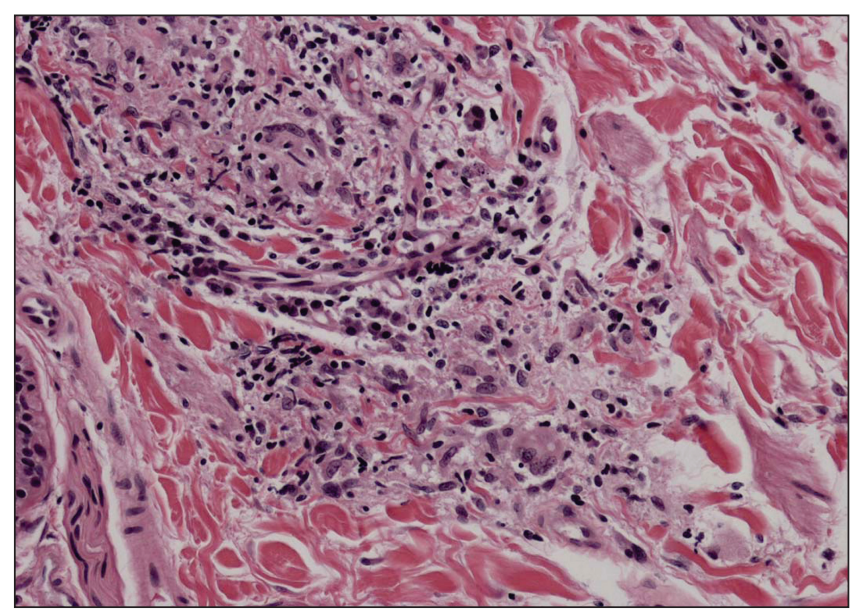

Figure 1) Vulvar biopsy, showing loose, ill-defined, granulomatous inflammation in the dermis, consistent with cutaneous involvement by Crohn's disease

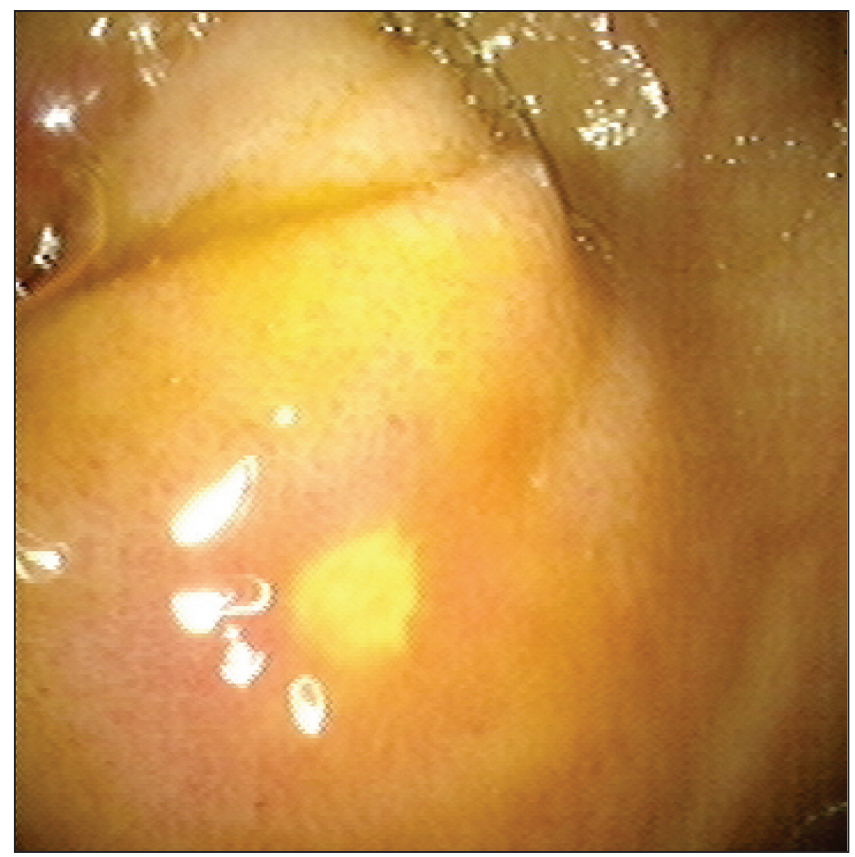

Figure 2) Recurrent Crohn's disease at colorectal anastamosis

therapy for her vulvar CD. She received a single induction dose of $5 \mathrm{mg} / \mathrm{kg}$ of infliximab and continued with her azathioprine treatment. She had an initial response to the therapy, with decreases in labial swelling, erythema and induration. She completed induction dosing (300 mg) after two and six weeks. Within two months, the skin of the vulva was significantly improved and vulvar biopsy showed resolution of the vulvar granulomatosis (Figure 4). The patient has continued to be in remission with respect to her vulvar $\mathrm{CD}$. Maintenance therapy has consisted of episodic infliximab therapy, as dictated by symptoms, due to limitations in drug access.

\section{DISCUSSION}

$\mathrm{CD}$ is a chronic inflammatory disorder that can affect any portion of the gastrointestinal tract. Although gynecological presentations of $\mathrm{CD}$ are described, the diagnosis is often delayed, because the patients are usually referred to multiple specialists before the diagnosis is made. Involvement of the

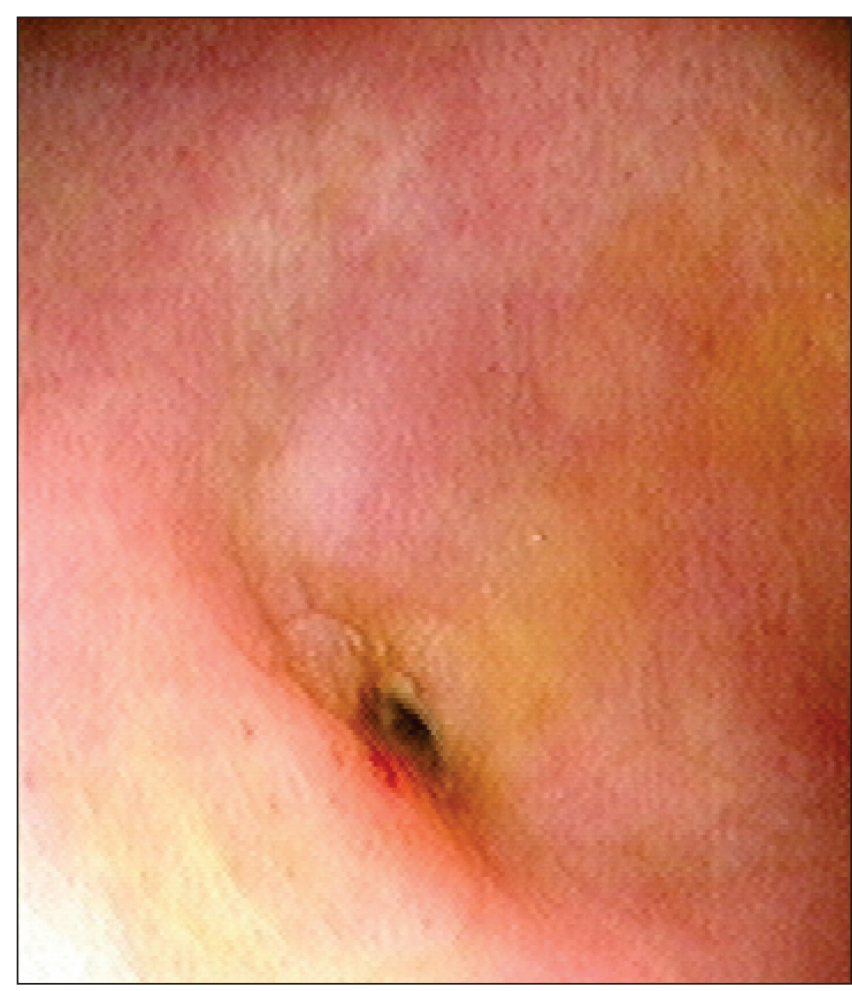

Figure 3) Internal os of fistula rectum

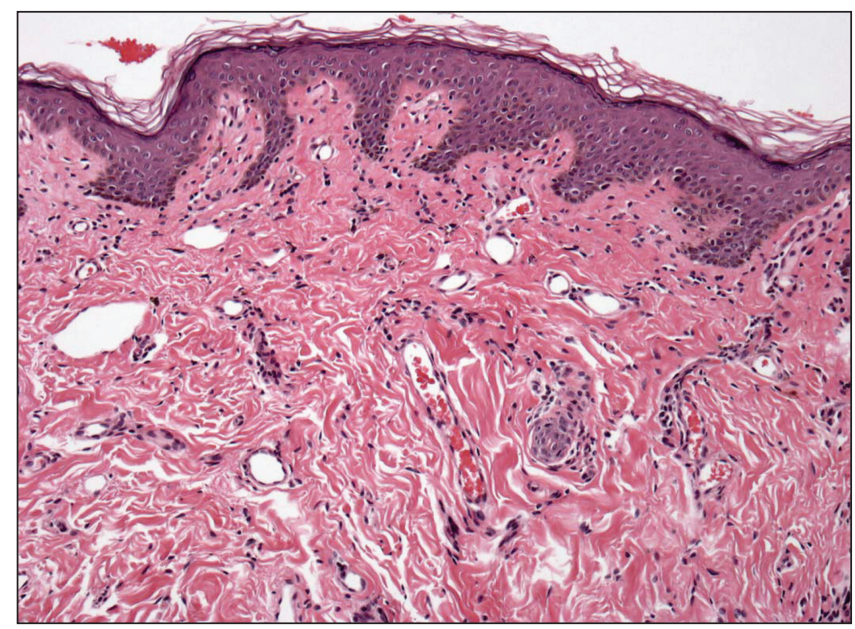

Figure 4) Vulvar biopsy postinfliximab therapy showing no evidence of dermal granulomatous inflammation

vulva can occur either from direct extension from the perineal region, or due to metastatic disease. Metastatic CD is defined as having granulomatous lesions of $\mathrm{CD}$ in an area that is noncontiguous to the gastrointestinal tract. A retrospective review by Ploysangam et al (2) of 80 cases of metastatic CD demonstrated that $56 \%$ of women had gynecological involvement. The exact pathogenesis of metastatic CD is unknown, although it has been proposed that a T lymphocytemediated type IV reaction could be partially responsible (3). The common vulvar lesions of CD are ulcerations with or without edema and fistulas, but previous nonulcerating lesions, such as chronic epitheloid cell granulomas, have been reported. Few cases have solely vulvar manifestations of CD that preceded gastrointestinal involvement (4). In the English literature, there are presently only 25 reported cases 
of isolated vulvar $\mathrm{CD}$, of which, in nine patients, the vulvar involvement represented their initial presentation of CD.

Multiple cutaneous lesions can be associated with CD, with the most common being perianal and peristomal ulceration. Other cutaneous manifestations that are strongly associated with CD include erythema multiforme, erythema nodosum and pyoderma gangrenosum (5). The first case of metastatic CD was described in 1965 by Parks et al (6). Although there have been few case reports in the literature about this entity, it is still recognized as an uncommon manifestation of CD. Case reports thus far have reported metastatic $\mathrm{CD}$ in the facial, truncal and penile regions. Usually, the cutaneous lesions are in the inguinal and perineal areas, because they are areas of increased moisture (7).

The Melkersson-Rosenthal syndrome is an idiopathic syndrome associated with $\mathrm{CD}$ that is characterized by recurrent facial swelling, relapsing paralysis of the face and a fissured tongue (8). Occasionally, genital lesions may also be present. Cheilitis granulomatosis may occur as part of this syndrome or by itself. Some case reports have suggested thalidomide as a treatment option for patients who are resistant to the standard therapies (9). Thalidomide inhibits the actions of tumour necrosis factor-alpha; however, because of its known teratogenicity, it has not gained wide acceptance.

Although many metastatic CD lesions resolve spontaneously, treatment of metastatic CD of the vulva has consisted of typical topical and systemic therapies used to treat inflammatory bowel disease. Before commencing medical therapy, deep fistulas and pelvic abscesses need to be excluded by physical examination, including proper internal pelvic examination, examination under anesthesia and appropriate imaging, which may include endovaginal ultrasound, computed tomography scan of the pelvis and/or pelvic magnetic resonance imaging. In the literature, treatment of vulvar CD has included corticosteroids, azathioprine, systemic sulfasalazine, cyclosporine and long-term metronidazole. In 2003, Bens et al (10) reported a case of complete regression of pyostomatitis vegetans of the mouth and vulva as the result of therapy with methotrexate and infliximab at zero, two and six weeks. In that reported case, vulvar lesions had neutrophilic microabscesses without granulomas. More recently, a case of vulvitis granulomatosa associated with Melkersson-Rosenthal syndrome was successfully treated with tranilast (11). The release of both interleukin-2 and interferon-gamma from the $\mathrm{T}$ helper cells is inhibited by tranilast, thus inhibiting the formation of multinucleated giant cells from peripheral monocytes (12) and eventual granulation. In the present case, although the clinical appearance of vulvar involvement improved, there was no evidence of biopsy-proven resolution of the disease post-treatment.
Infliximab is a chimeric monoclonal immunoglobulin G1 antibody to tumour necrosis factor-alpha and is often used in conjunction with an immunomodulator to treat moderate to severe and fistulizing CD. Infliximab has shown its effectiveness as a treatment for other cutaneous diseases associated with CD such as orofacial CD (13) and pyoderma gangrenosum (5). There were no prior reports of infliximab use for primary CD of the vulva.

\section{SUMMARY}

The present paper reports the first case of a patient with metastatic CD to the vulva that went into complete symptomatic and histopathological remission when treated with infliximab combined with azathioprine. Further experience is required for the initiation of infliximab in metastatic CD to the vulva, with long-term follow-up to assess any potential relapses in treatment.

\section{REFERENCES}

1. Donaldson LB. Crohn's disease: "Its gynecologic aspect". Am J Obstet Gynecol 1978;131:196-202.

2. Ploysangam T, Heubi JE, Eisen D, Balistreri WF, Lucky AW. Cutaneous Crohn's disease in children. J Am Acad Dermatol 1997;36:697-704.

3. Shum DT, Guenther L. Metastatic Crohn's disease. Case report and review of the literature. Arch Dermatol 1990;126:645-8.

4. Guerrieri C, Ohlsson E, Ryden G, Westermark P. Vulvitis granulomatosa: A cryptogenic chronic inflammatory hypertrophy of vulvar labia related to cheilitis granulomatosa and Crohn's disease. Int J Gynecol Pathol 1995;14:352-9.

5. Burgdorf W. Cutaneous manifestations of Crohn's disease. J Am Acad Dermatol 1981;5:689-95.

6. Parks AG, Morson BC, Pegum JS. Crohn's disease with cutaneous involvement. Proc R Soc Med 1965;58:241-2.

7. Guest GD, Fink RL. Metastatic Crohn's disease: Case report of an unusual variant and review of the literature. Dis Colon Rectum 2000;43:1764-6.

8. Hornstein OP. Melkersson-Rosenthal syndrome - a challenge for dermatologists to participate in the field of oral medicine. J Dermatol 1997;24:281-96.

9. Thomas P, Walchner M, Ghoreschi K, Rocken M. Successful treatment of granulomatous cheilitis with thalidomide. Arch Dermatol 2003;139:136-8.

10. Bens G, Laharie D, Beylot-Barry M, et al. Successful treatment with infliximab and methotrexate of pyostomatitis vegetans associated with Crohn's disease. Br J Dermatol 2003;149:181-4

11. Tsuboi H, Masuzawa M, Katsuoka K. A case of vulvitis granulomatosa. J Dermatol 2005;32:831-4.

12. Mizuno K, Okamoto H, Horio T. Inhibitory influences of tranilast on multinucleated giant cell formation from monocytes by supernatant of concanavalin A-stimulated mononuclear cells. J Dermatol Sci 2000;24:166-70.

13. Chen W, Blume-Peytavi U, Goerdt S, Orfanos CEl. Metastatic Crohn's disease of the face. J Am Acad Dermatol 1996;35:986-8. 


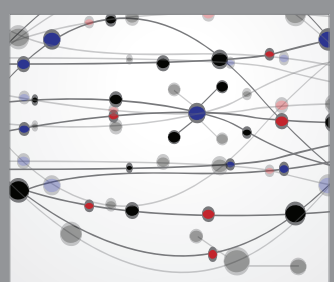

The Scientific World Journal
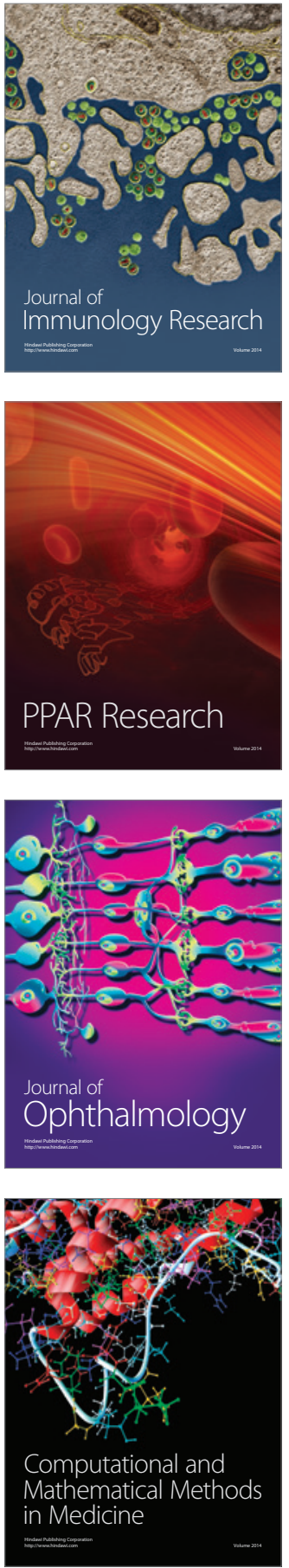

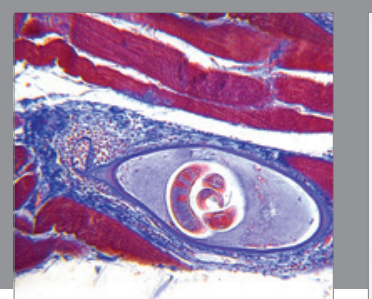

Gastroenterology Research and Practice

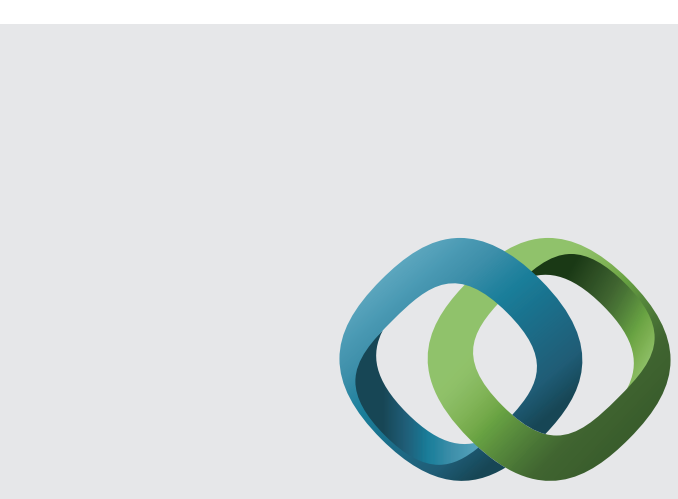

\section{Hindawi}

Submit your manuscripts at

http://www.hindawi.com
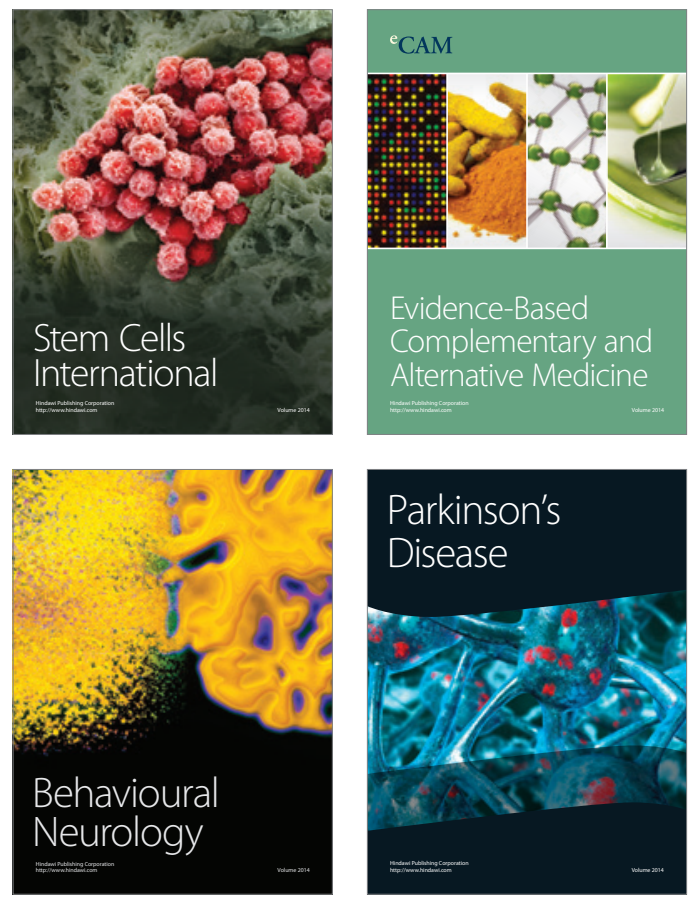
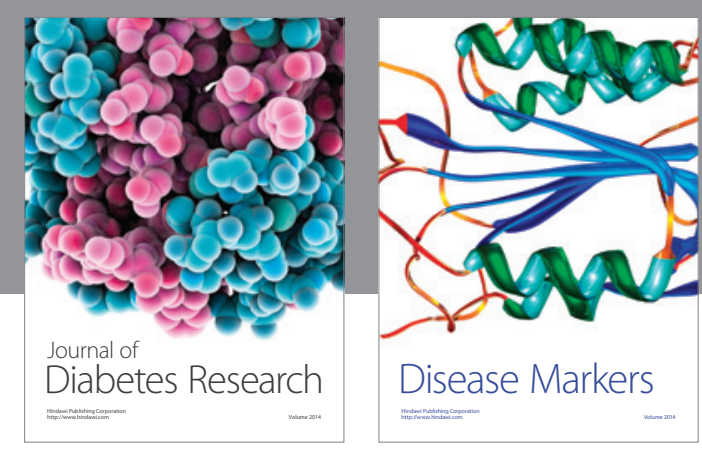

Disease Markers
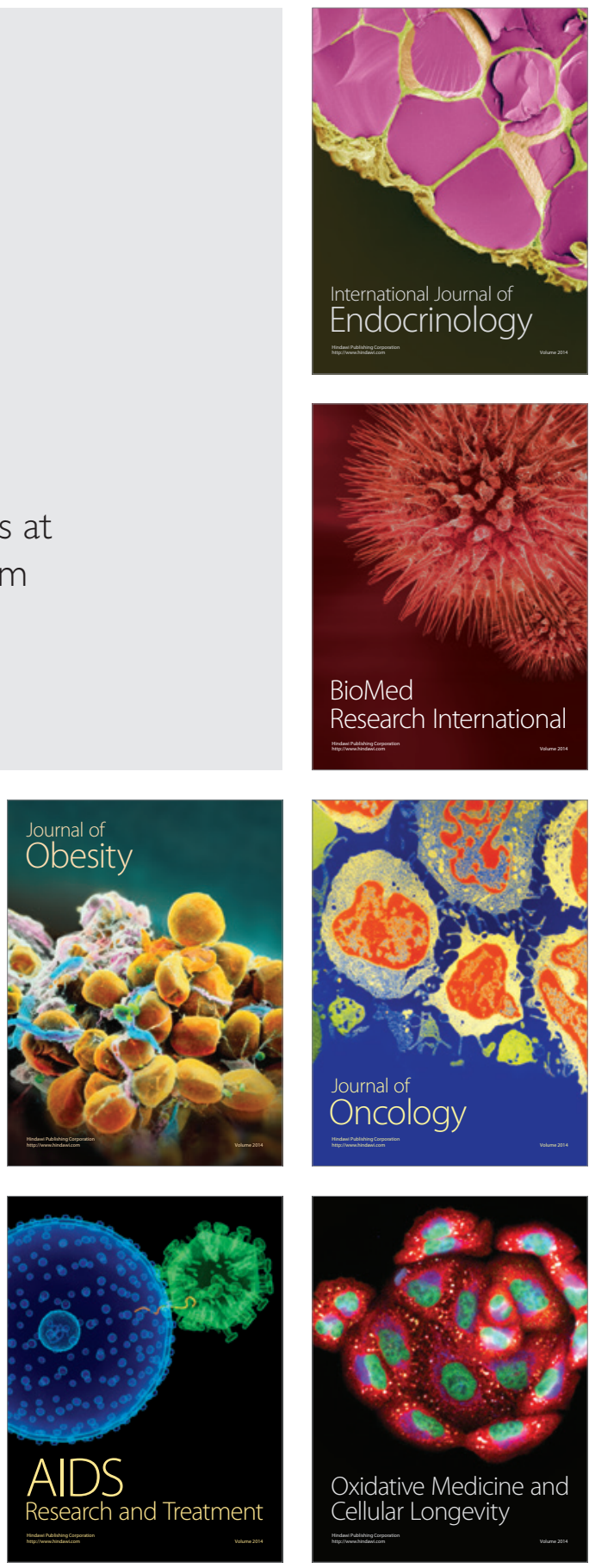